\title{
INTELECTUAIS ENVERGONHADOS: CENSURA DE ROMANCES POPULARES PORNOGRÁFICOS E LUTA DE CLASSES DURANTE O REGIME CIVIL-MILITAR BRASILEIRO (1964-1985)
}

\author{
Rodolfo Rorato Londero ${ }^{1}$
}

Resumo: O objetivo deste artigo é discutir o papel dos intelectuais durante o último regime civil-militar brasileiro (1964-1985), principalmente a indiferença em relação à censura de romances populares pornográficos, como os de Cassandra Rios e Adelaide Carraro, autoras enfocadas neste estudo. Enquanto hipótese, o artigo identifica o motivo da indiferença por meio de duas condições específicas: (1) a "alienação" política e/ou a "inferioridade" literária das autoras, tornando-as cúmplice do "vazio cultural" que assolou a década de 1970; e (2) a sensibilidade popular das autoras. Conclui-se neste caso que a indiferença dos intelectuais ratificou a censura do Estado.

Palavras-chave: classe intelectual; literatura popular; censura; regime civil-militar brasileiro (1964-1985).

Abstract: The aim of this paper is to discuss the role of intellectuals during the last Brazilian civil-military regime (1964-1985), specially the indifference about the censorship of pornographic popular novels, such as works by Cassandra Rios and Adelaide Carraro, writers focused in this study. The hypothesis of this paper identifies the reason for the indifference through two specific conditions: (1) the policy "alienation" and/or the literary "inferiority", making these writers accomplices to "cultural void" that plagued the 1970's, and (2) the popular sense of these writers. We conclude in this case that the indifference of intellectuals ratified state censorship.

Keywords: intellectual class; popular literature; censorship; Brazilian civil-military regime (1964-1985).

\begin{abstract}
Quando as pessoas fazem campanha pela liberação da literatura erótica, geralmente estão pensando em Joyce ou Miller. Minha dúvida é: na hora do naufrágio, esses intelectuais teriam coragem de colocar Cassandra Rios no bote salva-vidas? Ou a salvação é apenas para os que são também intelectuais? A arte "redime" o erotismo? É preciso ser uma grande obra literária para que os intelectuais se mobilizem contra sua proibição? (Braulio Tavares, "Livros proibidos III")
\end{abstract}

\footnotetext{
${ }^{1}$ Doutor em Estudos Literários pela Universidade Federal de Santa Maria (UFSM). Professor Adjunto do Departamento de Comunicação da Universidade Estadual de Londrina (UEL).
} 
As perguntas inquietantes levantadas por Braulio Tavares na epígrafe acima, em um dos seus quatros textos dedicados à Semana dos Livros Proibidos - evento norteamericano que celebra, desde 1982, a liberdade de expressão -, revela alguns problemas mal resolvidos, principalmente a respeito do papel da classe intelectual em relação à censura de romances populares pornográficos durante o último regime civil-militar brasileiro (1964-1985). No primeiro dos textos, Tavares lembra que "a luta pela liberdade de expressão não é uma luta do Bem contra o Mal, a luta dos Cem Por Cento Certos contra os Cem Por Cento Errados", pois "todo mundo é a favor [da liberdade de expressão] até o instante em que se torna vítima dessa liberdade, até quando surge um livro dizendo algo que nos ofende, nos envergonha ou nos ameaça"2. Ao evocar a responsabilidade de cada indivíduo na realização ou não da censura, as palavras de Tavares também atingem o problema da formação dos regimes ditatoriais, muitas vezes interpretados como resultantes de "instituições e práticas coercitivas e manipulatórias", ao invés de "produto social" (ROLLEMBERG; QUADRAT, 2010, p. 11). Esquece-se que mais de um milhão de pessoas participaram da marcha em comemoração ao golpe de 64 . Esquece-se que, por trás de cada livro proibido, havia uma ou mais denúncias, provindas justamente de pessoas que se sentiram ofendidas, envergonhadas ou ameaçadas por liberdades que expressavam aquilo que elas consideravam pornográfico ou subversivo.

Para retornar à dúvida de Tavares, pode-se perguntar qual era a responsabilidade dos intelectuais durante o último regime civil-militar: apesar de não denunciá-las, por que eles se sentiam envergonhados em defender as obras de Cassandra Rios e Adelaide Carraro? E por que eles se sentem assim até hoje, não incluindo as autoras nos debates contemporâneos? Campeãs de vendagem ao longo do período referido, ambas as autoras amargaram, respectivamente, 17 e 13 livros censurados ${ }^{3}$. Considerando as obras das duas autoras como exemplos de literatura popular do período analisado, este artigo apresenta como hipótese duas condições específicas que originaram essa vergonha intelectual: (1) a "alienação" política e/ou a "inferioridade" literária das autoras, tornandoas cúmplice do famoso "vazio cultural" da década de 1970, mas também as excluindo dos

\footnotetext{
2 Disponível em: <http://mundofantasmo.blogspot.com.br/2011_09_24_archive.html>. Acesso em 10 out. 2012.

3 Dados baseados em levantamento realizado por Reimão (2011, p. 127), além de consulta própria em jornais e revistas. É provável que esses números sejam bem maiores, apesar da dificuldade de verificá-los livro por livro: uma reportagem do jornal Folha de S. Paulo (20 de junho de 1977) contabilizava 28 romances apreendidos de Cassandra e onze de Adelaide.
}

Revista Eletrônica Literatura e Autoritarismo, no 21- Janeiro-Junho de 2013 - ISSN 1679-849X |135 http://cascavel.ufsm.br/revistas/ojs-2.2.2/index.php/LA/about/index 
debates atuais, como entre literatura referencial e autorreferencial; e (2) a própria sensibilidade popular das autoras.

Um dos grandes paradoxos brasileiros da década de 1970 resume-se à expressão "vazio cultural", pois enquanto a crítica intelectual alardeava-o, a indústria cultural brasileira experimentava um crescimento nunca antes registrado. Como se pode demonstrar por meio de ensaios da época e estudos posteriores, esse paradoxo somente faz sentido caso se considere a origem frankfurtiniana do conceito de indústria cultural ${ }^{4}$ : organização e planificação da produção cultural (HORKHEIMER; ADORNO, 1969, p. 158), atrofia da imaginação e da espontaneidade do consumo cultural (HORKHEIMER; ADORNO, 1969, p. 163). Portanto, diante desta lógica, mesmo produzindo cultura em escala industrial, o país continuava vazio.

Ao prognosticar o "vazio cultural" da década de 1970 para a revista Visão (julho de 1971), Ventura demonstra que, além do Al-5 e da censura, as causas deste vazio também se devem à "emergência de uma 'cultura industrializada' cada vez mais condicionada pelas leis da produção" (VENTURA, 2000, p. 48). Os estudos mais recentes sobre a literatura brasileira da década de 1970 não diferem da análise acima. Em Gavetas vazias (1996), ainda que problematize a expressão "vazio cultural" ${ }^{5}$, Tânia Pellegrini identifica um panorama cultural desalentador devido à censura e ao crescimento da indústria cultural (PELLEGRINI, 1996, p. 9). Em artigo mais recente, a autora compreende as políticas de incentivo do governo Geisel ao crescimento da indústria cultural como "a 'estrutura mais profunda' da censura", objetivando "uma espécie de equalização do controle estatal sobre todo o processo cultual” (PELLEGRINI, 2008, p. 41): enquanto a legislação censória proibia as manifestações desfavoráveis ou indesejáveis, as políticas cultuais incentivavam as manifestações de interesse do Estado.

\footnotetext{
${ }^{4}$ É provável que os críticos adotassem esta origem do conceito, ainda mais considerando que, entre os ensaístas brasileiros, se percebia "a influência de marxistas como Lukács e de pensadores inspirados no marxismo, como Theodor Adorno e Walter Benjamin", como relata Candido (1977, p. 7) em "A literatura brasileira em 1972". Neste sentido, segundo Napolitano, o termo "vazio cultural" surgiu "para nomear (e desqualificar) a sensação de perda repentina da hegemonia cultural no seio da esquerda pelo Partido Comunista e sua esfera de influência", principalmente em relação aos meios de comunicação (NAPOLITANO, 2010, p. 164).

${ }^{5}$ Pellegrini questiona o conceito de reflexo adotado nas interpretações do "vazio cultural", como se a criação literária resultasse simplesmente do reflexo da estrutura econômica, política e social (PELLEGRINI, 1996, p. 9-11). Este conceito é próprio das primeiras interpretações marxistas do modelo base-superestrutura (LONDERO, 2010). Em seu artigo para a revista Visão, Ventura compartilha dessa interpretação mecanicista ao afirmar que "a cultura vive uma fase de transição em que, como superestrutura, tenta adaptar-se às alterações infraestruturais surgidas no país” (VENTURA, 2000, p. 47).
}

Revista Eletrônica Literatura e Autoritarismo, no 21- Janeiro-Junho de 2013 - ISSN 1679-849X $\mid 136$ http://cascavel.ufsm.br/revistas/ojs-2.2.2/index.php/LA/about/index 
Do mesmo modo, em Itinerário político do romance pós-64 (1998), Renato Franco associa a expansão e consolidação da indústria cultural ao "próprio processo de modernização conservadora imposto ao país, de modo autoritário, pelos governos militares", sendo este processo responsável por fustigar as "ondas de mudança" da produção cultural (FRANCO, 1998, p. 25). Franco também estabelece uma equação entre esse processo de modernização e a censura, mas privilegiando o comprometimento do regime com o capital estrangeiro: ao "eliminar as condições materiais tradicionais de produção e circulação da cultura nacional", a censura acelerava o desenvolvimento da indústria cultural e criava "uma espécie de reserva de mercado para a produção dos países hegemônicos" (FRANCO, 1998, p. 79). Este argumento não se sustenta por dois motivos, pois o regime (1) censurou mais obras estrangeiras que nacionais e (2) também repudiava o produto cultural massificado, como expôs em sua Política Nacional de Cultura, elaborada pelo Ministério da Educação e Cultura em 1975 (NAPOLITANO, 2010, p. 155).

Flora Süssekind, por sua vez, percebe o espetáculo como tática do regime antes da década de 1970, portanto, antes do "vazio cultural": ao incentivar o desenvolvimento dos meios de comunicação, principalmente da televisão, o governo Castelo Branco (19641967) acabou por isolar os escritores sem a necessidade de censurá-los, pois "deixava-se a intelectualidade bradar denúncias e protestos, mas os seus possíveis espectadores já tinham sido roubados pela televisão" (SÜSSEKIND, 2004, p. 24). O que a autora de Literatura e vida literária (1985) não percebe ou não quer perceber é que ainda assim havia público para uma literatura popular, como atesta o enorme sucesso de Cassandra e Adelaide. Esta literatura tanto incomodou que obrigou o regime a adotar outras táticas além do espetáculo, como é o caso da censura prévia legalizada pelo Decreto-lei n.o 1.077, em janeiro de 1970. Não é demais lembrar que este decreto vetou majoritariamente obras populares.

No balanço realizado para a coleção Anos 70 , onde a produção cultural dos primeiros anos da década de 1970 também é compreendida como "comercial e digestiva" (HOLLANDA; GONÇALVES, 1980, p. 39), Heloísa Buarque de Hollanda e Marcos Gonçalves apresentam autores e obras que escapam da aparente força centrípeta criada pelo buraco negro do "vazio cultural", sendo os mesmos autores e obras destacados em estudos posteriores, ainda que por motivos diferentes (PELLEGRINI, 1996; FRANCO, 


\section{Literatura e Autoritarismo}

Identidade, memória e representações culturais

1998; SÜSSEKIND, 2004), o que transforma esta seleção em um "cânone" do período: Incidente em Antares (1971), de Érico Veríssimo; Zero (1975), de Ignácio de Loyola Brandão; Quatro olhos (1976), de Renato Pompeu; A festa (1976), de Ivan Ângelo; Armadilha para Lamartine (1976), de Carlos \& Carlos Sussekind; $O$ que é isso, companheiro? (1979), de Fernando Gabeira; entre outros. O título Política e literatura, do artigo de Hollanda e Gonçalves, é emblemático para se compreender o principal valor desse cânone, cabendo a ele a mesma crítica realizada pela historiografia social contemporânea: a supervalorização do fator político como explicação do processo histórico que marcou os anos de autoritarismo (MARCELINO, 2006, p. 15).

O vetor político também orienta a narrativa histórica apresentada em 1968: o ano que não terminou, onde Ventura traça um interessante quadro sobre o crescimento do mercado editorial ao final da década de 1960, indicando a demanda por "algumas inevitáveis futilidades", mas também por "livros de densas ideias" e "refinadas obras de ficção": "Nas listas de best-sellers, convivem nomes como Marx, Mao, Guevara, Debray, Lukács, Gramsci, James Joyce, Hermnan Hesse, Norman Miller e, claro, Marcuse" (VENTURA, 2008, p. 54-55). Apenas para imaginar quais seriam essas "inevitáveis futilidades", pois o autor não se preocupa em identificá-las, vale a pena procurar por referências bibliográficas pouco comuns em historiografias sociais e literárias, como um Almanaque Anos 70 (2006): "No país dos machões, na era dos generais, as campeãs de vendagem de livros eram duas mulheres: Cassandra Rios e Adelaide Carraro" (BAHIANA, 2006, p. 92).

Apesar da popularidade e do incômodo que causavam aos censores, é fácil entender porque os romances de Cassandra e Adelaide não pertencem ao "cânone" referido acima. Em primeiro lugar, seguindo o raciocínio das causas do "vazio cultural", a condição de best-seller das autoras tornava-as cúmplices deste vazio na medida em que elas alimentavam a indústria cultural. Entretanto, muitos dos romances das autoras foram publicados por editoras clandestinas, ou seja, por editoras à margem do processo de modernização do mercado editorial. Somente com o fim do Decreto-lei n. 01.077 em fevereiro de 1980 que as obras de Cassandra e Adelaide foram republicadas por grandes editoras: Record e Global, respectivamente (GONÇALO JUNIOR, 2012, p. 32). Isto coloca em xeque a relação entre as autoras e o crescimento da indústria cultural brasileira, pelo menos durante o período estudado.

Revista Eletrônica Literatura e Autoritarismo, no 21- Janeiro-Junho de 2013 - ISSN 1679-849X $\mid 138$ http://cascavel.ufsm.br/revistas/ojs-2.2.2/index.php/LA/about/index 
Em segundo lugar, as autoras não abordaram a tão exigida temática política, pelo menos não como os críticos esperavam que este tema fosse abordado. Adelaide sempre se considerou uma escritora de denúncias sociais e políticas (o problema dos menores abandonados, a situação precária dos presídios e sanatórios, a violência policial contra prostitutas, a desonestidade dos políticos, etc.), mas a crítica sociológica destaca a sexualidade como tema central de sua obra (CALDAS, s/d, p. 82). Por outro lado, Cassandra nunca quis escrever livros engajados, "nunca quis pertencer a nenhuma igrejinha" (RIOS, 2001, p. 11), mas a crítica queer a elege como a primeira autora brasileira que "lutou para dar voz, de uma forma real e humana, a gays, lésbicas e transexuais" (SANTOS, 2005, p. 9). Faz isto depois de afastá-la de rótulos popularescos, como se assim "canonizasse" a obra da autora: na apresentação crítica e atualizada de Uma mulher diferente (1965), Santos afirma que "são precisamente essa função reflexiva e o compromisso político e histórico que diferenciam Cassandra Rios de autores como Adelaide Carraro e Carlos Zéfiro, cujas obras eram produzidas simplesmente como objeto cultural com fins lucrativos" (SANTOS, 2005, p. 10). Esforço em vão da crítica queer, pois tanto as obras de Cassandra quanto as de Adelaide parecem passar longe da matéria política que informa as obras "canônicas" do período.

Em terceiro lugar, sobre o valor literário das obras das autoras, a posição dos intelectuais não é muito diferente da dos censores: "Pode-se, com efeito, depreciar este ou aquele livro, mas quando a obra em exame trata de sexo fora dos cânones autorizados para sua expressão, negar-lhe estatuto específico é sempre a estratégia mais à mão e mais rapidamente sacada pelos poderes censórios em qualquer tempo" (SILVA, 1989, p. 156). Contudo, ao contrário da severidade dos censores em relação à temática sexual (no caso do regime de 64, nem mesmo o inquestionável valor artístico de Picasso impediu a censura de suas gravuras eróticas em 1972), o que incomoda os intelectuais não é o conteúdo erótico em si (basta lembrar a fama de Sade entre críticos do porte de Barthes, Foucault e Deleuze), mas sim "o conteúdo de Cassandra e Adelaide [tratar-se] não apenas de um erotismo [...], mas de um erotismo pobre, de pobre, de semiletrado" (VIEIRA, 2010, p. 23).

Mais que o erotismo pobre, ponto que não se pretende discutir aqui, o erotismo de pobre incomoda os intelectuais, pois é como se a presença das autoras representasse "uma inadequação do ponto de vista da normatividade social em vigor. Algo como uma 
empregada doméstica sentando-se à mesa de jantar de um lar burguês" (VIEIRA, 2010, p. 23). Não é por outro motivo que Silva (1989, p. 47) compreende a censura enquanto luta de classes entre o Estado, defensor dos interesses da classe dominante, e o escritor, em oposição a esses interesses. Na verdade, a metáfora da empregada é adotada por Vieira para definir os romances populares pornográficos de Cassandra e Adelaide: "E os chamamos assim, literatura de empregada, seguindo a sugestão da cena em que uma jovem diarista contamina de literatura, uma literatura intumescida, encharcada de gozo, a casa de seus patrões" (VIEIRA, 2010, p. 45; grifo nosso). Vieira afirma que não pretende utilizar o termo com precisão sociológica, mas supõe que "obras consumidas por milhões, no Brasil, sejam obras que caíram no gosto das classes subalternas" (VIEIRA, 2010, p. 40). Também não é objetivo deste artigo determinar o público específico das obras das autoras, até porque isto não faz muito sentido tratando-se de romances de grande circulação, mas é interessante apresentar outros dados que permitem esclarecer ainda mais sobre essas leitoras subalternas: em sua enquete sobre leituras operárias, realizada em 1970, Bosi constatou que apenas 29\% das entrevistadas compraram algum livro em toda a sua vida, sendo os empréstimos ou as doações de colegas a forma mais comum das operárias conseguirem livros (BOSI, 2000, p. 157-158). O quadro apresentando por Bosi é bastante compreensível, ainda mais considerando as políticas de arrocho salarial tão comuns durante o período estudado (ALVES, 2005), fazendo da cultura o primeiro item riscado da lista de necessidades das classes proletárias. Isto fez provavelmente da classe média o principal comprador e consumidor das obras das autoras, invertendo assim o fluxo de "contaminação" produzido pela literatura de empregada, pois se as empregadas, como as operárias entrevistadas por Bosi, compravam poucos livros, então era mais frequente elas emprestarem esses livros não de outras empregadas, mas sim de pessoas que compravam livros. Contudo, o que interessa não é o fluxo da literatura de empregada, mas como este termo aponta para uma literatura que retoma a sensibilidade das classes populares.

Para Martín-Barbero, "a nova cultura, a cultura de massa, começou sendo uma cultura que não era apenas dirigida às massas, mas na qual elas encontravam retomadas, desde a música até as novelas de rádio e o cinema, algumas de suas formas de ver o mundo, senti-lo e expressá-lo" (MARTíN-BARBERO, 2006, p. 227). Ainda que a massa não a produza, como esclarece o conceito de indústria cultural, a cultura é de 
massa, pois retoma sua experiência e também sua forma popular de manifestação artística, já que "o massivo foi gerado lentamente a partir do popular" (MARTíNBARBERO, 2006, p. 175). Da literatura de cordel ao jornalismo sensacionalista, do teatro popular renascentista à telenovela, do ilusionismo circense ao cinema de efeitos especiais, Martín-Barbero não percebe uma cisão entre indústria cultural e cultura popular como querem os frankfurtianos, mas sim um mesmo processo cultural. Igualmente, em seu estudo sobre os usos do letramento pela classe operária inglesa, Hoggart traça uma linha que liga as aventuras de Moll Flanders (1722) aos romances baratos de sexo e violência do século $X X$, embora estes se diferenciem por "um modo claustrofóbico e doentio" (HOGGART, 1981, p. 260). Em todo caso, desde o apelo verídico e moralista do prefácio ("Ao escrever Asco, lancei um libelo, traduzindo em palavras, todo o asco que sentimos ao saber da depravação em que caem moças e rapazes ingênuos, cujo único objetivo é o caminho ao estrelato", escreveu Adelaide no prefácio do romance referido) até os constantes desencontros e infortúnios, Moll Flanders parece se atualizar nos enredos de Adelaide, principalmente. Aliás, do mesmo modo que os romances de Cassandra e Adelaide são literatura de empregada, o romance de Defoe era, no século XVIII, literatura de criados e aprendizes, apesar de adquirido principalmente por comerciantes e donos de lojas (WATT, 2007, p. 44). Isto porque a personagem homônima de Defoe, também uma aprendiz de costureira, expressava a sensibilidade das classes populares da época, tal como fizeram as personagens de Cassandra e Adelaide em tempos mais recentes.

A (rejeição à) sensibilidade popular parece explicar porque os intelectuais pouco se manifestaram quando os romances de Cassandra e Adelaide foram seguidamente vetados, deixando livre o curso da censura nesses casos. O poeta e jornalista Nei Duclós, em artigo publicado no jornal Folha de S. Paulo (18 de fevereiro de 1979), se mostrou categórico a respeito do assunto:

A maioria dos livros proibidos é de baixa qualidade, pornografia estrangeira com mulheres nuas na capa. A intelectuália fica no maior silêncio quando se trata desse tipo de "literatura". Mas costuma gritar quando livros mais importantes, como Feliz ano novo e Zero, vão para a fogueira (isso não é um sentido figurado: os livros são queimados mesmo). Se todo mundo tivesse gritado quando Adelaide Carraro começou a ser perseguida pela censura, o movimento estaria mais moralizado e também mais eficiente. Enquanto isso, o Ministério da, digamos, Justiça, age rapidamente: a

Revista Eletrônica Literatura e Autoritarismo, no 21- Janeiro-Junho de 2013 - ISSN 1679-849X |141 http://cascavel.ufsm.br/revistas/ojs-2.2.2/index.php/LA/about/index 
média, neste fim de governo, é de quase um livro por dia (DUCLÓS, 1979, p. 13).

Apesar do evidente exagero quanto ao número de livros censurados em 1979 Reimão (2011) calculou 38 livros -, o trecho remete ao "Manifesto dos 1.046 Intelectuais contra a Censura", documento assinado em 25 de janeiro de 1977 por Antonio Candido, Jorge Amado, Chico Buarque, Dias Gomes, João Ubaldo Ribeiro, Paulo Emilio Salles Gomes, entre outros ${ }^{6}$. A censura de Feliz ano novo (1975), de Rubem Fonseca, e principalmente de Zero, ambas no final de 1976, motivou o manifesto, como informa o autor deste último livro, Ignácio de Loyola Brandão ${ }^{7}$. Se apenas esses dois livros censurados foram capazes de reunir tantos intelectuais indignados contra a censura, por que os 17 de Cassandra e os 13 de Adelaide não conseguiram a mesma mobilização? Não se trata, em todos os casos, de cerceamento à liberdade de expressão? Ou algumas liberdades são "melhores" que outras? No caso das autoras, o desconhecimento da censura não se justificava, pois os vetos eram constantemente noticiados, chegando ao ponto do jornal Folha de S. Paulo (16 de janeiro de 1978) afirmar que "já não é surpresa nenhuma o [ministro] Falcão proibir um livro de Adelaide Carraro".

Não por acaso, à margem dos romances de Cassandra e Adelaide, Feliz ano novo e Zero são alguns dos livros destacados nos atuais debates sobre a literatura brasileira da década de 1970 (SILVA, 1989; PELLEGRINI, 1996; REIMÃO, 2011). Na verdade, as próprias categorias teóricas envolvidas nestes debates muitas vezes impedem qualquer aproximação aos romances populares ${ }^{8}$, lembrando mais uma atualização de polêmicas específicas do período, como é o caso do embate entre literatura engajada e literatura de vanguarda, exemplificado por quem o atravessou de um extremo ao outro, o poeta Ferreira Gullar (ver neste sentido seu ensaio Vanguarda e Subdesenvolvimento,

\footnotetext{
${ }^{6}$ Em sua última entrevista antes de falecer, Cassandra lembrou que "uma vez até tiraram [seu] nome de um manifesto contra a censura, assinado por vários artistas" (RIOS, 2001, p. 11), provavelmente se referindo ao "Manifesto dos 1.046 Intelectuais contra a Censura". Sendo um nome "marcado" entre os censores da DCDP, os demais artistas e intelectuais provavelmente resolveram retirar Cassandra do manifesto. Contudo, não se pode desconsiderar o preconceito artístico em relação à sua obra ou mesmo o posicionamento de Cassandra, às vezes favorável à censura (ver o primeiro tópico do quarto capítulo).

Disponível em: <http://www.jornaldelondrina.com.br/online/conteudo.phtml?id=1045266>. Acesso em: 10 ago. 2012.

${ }^{8}$ Exceção ao estudo de Silva que, apesar de analisar o processo jurídico envolvendo a censura do livro de contos de Rubem Fonseca, não ignora "a contumácia das exclusões dos nomes de Adelaide Carraro e Cassandra Rios" entre os títulos proibidos durante o governo Geisel (SILVA, 1989, p. 17).
}

Revista Eletrônica Literatura e Autoritarismo, no 21- Janeiro-Junho de 2013 - ISSN 1679-849X |142 http://cascavel.ufsm.br/revistas/ojs-2.2.2/index.php/LA/about/index 
publicado em 1969, onde os dois extremos são igualmente apoiados e criticados). Pellegrini (1996) e Süssekind (2004) são quem atualmente polarizam esse debate: a primeira valoriza uma literatura cuja função é informar e testemunhar (seja por meio da alegoria ou de técnicas jornalísticas), engajamento necessário num regime que fazia prevalecer apenas a verdade oficial (PELLEGRINI, 1996, p. 24); a segunda aprecia o "trabalho com a linguagem", herança das vanguardas artísticas (SÜSSEKIND, 2004, p. 104). Ambas criticam a posição contrária: Süssekind fala em "recalque da ficcionalidade em prol de um texto predominantemente documental" (SÜSSEKIND, 2004, p. 104), crítica válida tanto para o romance-reportagem quanto para o romance fantástico, pois ambos se valem da alegoria enquanto "atalho para a realidade"9 (FRANCO, 1998, p. 146); Pellegrini afirma que a crítica de Süssekind tenta "neutralizar as reais contradições da sociedade que, de uma forma ou de outra, brotam das alegorias, dos testemunhos, dos romancespersonagens" (PELLEGRINI, 1996, p. 25).

Do mesmo modo que Pellegrini, Franco argumenta que Süssekind busca "defender uma concepção do romance que se afaste tanto da substância histórica como da vida política" (FRANCO, 1998, p. 146-147). Por sua vez, é necessário considerar que, ao valorizar o trabalho com a linguagem, Süssekind preza pelos "textos que incorporam a tensão política à sua própria linguagem, ao invés de apenas descrevê-la de modo mágico ou naturalista" (SÜSSEKIND, 2004, p. 47). Ou seja, a autora nem neutraliza nem afasta as contradições históricas e políticas, mas procura entendê-las como formas literárias. $\mathrm{Na}$ verdade, o que incomoda Süssekind é como a predominância do referencial, seja no realismo mágico ou no romance-reportagem, atendia aos objetivos do regime mesmo quando em forma de crítica e/ou denúncia:

É fácil reconhecer a censura como antagonista e até como coautora de desvios
estilísticos, linguagem alegórica, textos cifrados. Por outro lado, no incentivo à
produção, e sobretudo àquelas obras que retratem o país, não é comum perceber
outro adversário, com contornos ora de mecenas, ora de pai, mas tão ou mais
poderoso que a censura. Tão poderoso que faz vista grossa inclusive para a
divulgação de textos que se consideram "de denúncia" como os de um José
Louzeiro ou de João Antônio, porque neles, como na maior parte da literatura-
verdade do período, percebem colaboradores involuntários, mas bastante

${ }^{9}$ Segundo Franco (1998, p. 145), Süssekind faz uma interpretação equivocada do conceito benjaminiano de
alegoria explorado por Arrigucci Jr. em seu ensaio-entrevista "Jornal, realismo, alegoria" (1979). A relação
entre romance-reportagem e alegoria é assim exposta por Arrigucci Jr. ao citar Lúcio Flávio (1975), de José
Louzeiro: "É um romance apoiado na mediação da reportagem, e é um romance alegórico, que através de
um fato específico tende a aludir a uma situação mais geral - o quadro geral da violência - por meio de um
segmento social" (ARRIGUCCI JR., 1979, p. 80). Revista Eletrônica Literatura e Autoritarismo, no 21- Janeiro-Junho de 2013 - ISSN 1679-849X $\mid 143$ http://cascavel.ufsm.br/revistas/ojs-2.2.2/index.php/LA/about/index 


\section{Literatura e Autoritarismo}

eficientes. Isto porque servem ao mesmo senhor: ao interesse de representar literariamente um Brasil. E até o negativo da foto interessa à Política Nacional de Cultura. Em positivo ou negativo, o texto-retrato tende a ocultar fraturas e divisões, a construir identidades e reforçar nacionalismos pouco críticos (SÜSSEKIND, 2004, p. 46; grifos da autora).

Pellegrini (1996, p. 20) não compreende como denúncias poderiam interessar ao regime, justificando que elas driblavam a censura devido a outros fatores (o prestígio internacional de alguns autores, o pouco alcance da literatura em relação ao público, o sucesso da obra no exterior, etc.). Por outro lado, mais que ocultar divisões e reforçar nacionalismos, o negativo das denúncias fortalecia a narrativa legitimadora dos atos repressivos do regime: elas mostravam que o país realmente enfrentava uma "guerra interna", como apregoava o Manual Básico da Escola Superior de Guerra. Seguindo essa lógica, o país ainda não estava preparado para retornar à democracia, pois o caos político que a "revolução" buscou solucionar ainda persistia, o "espectro do comunismo" continuava a rondar o Brasil.

Mas por que então não permitir o retrato em negativo dos romances pornográficos, mostrando claramente um novo inimigo a combater, a "propaganda do sexo"? Por que os romances de Cassandra e Adelaide, que também retratavam o país - as autoras eram "continuadoras da tradição naturalista" (VIEIRA, 2010, p. 68) -, foram censurados? A própria Adelaide admitia, talvez para a alegria dos críticos, que não encontrava "valor literário", "aquelas descrições bonitas", em seus livros: "Meus livros têm o valor da mensagem. O brasileiro quer a realidade" (Folha de S. Paulo, 20 de junho 1977). Contudo, tanto sua literatura quanto a de Cassandra não buscavam "ocupar um certo vácuo criado pela censura" (PELLEGRINI, 1996, p. 24), informando ou testemunhado sobre fatos extraoficiais. A realidade que Cassandra e Adelaide retratavam não era a mesma de Gabeira, Veríssimo e Brandão, apenas para citar os três autores analisados por Pellegrini (1996), pois enquanto Cassandra dramatizava o universo homossexual, inclusive inspirada em pontos de encontro tradicionais (PIOVEZAN, 2005), Adelaide carregava o tom em denúncias sociais e políticas, como já se viu. Se a literatura das duas autoras cumpriu alguma função sob um regime autoritário, talvez seja a de enfrentar 
abertamente a censura, sem pseudônimos ou subterfúgios ${ }^{10}$, publicando ininterruptamente e mostrando, a cada livro censurado, o desrespeito do Estado à liberdade de expressão.

Diante do exposto, parece compreensível encontrar o problema da liberdade de expressão abordado em um livro cuja capa mostrava de antemão dois indícios perigosos: a autoria de Henry Miller e a ilustração de uma mulher nua, seios visíveis, se banhando num rio. Chama a atenção, entretanto, quem abordou o problema: o famoso crítico Otto Maria Carpeaux, em prefácio assinado em fevereiro de 1968, alguns meses antes do Al-5:

Nesses processos [contra obras caluniadas como sendo pornográficas], sempre a defesa citará, como contra-argumento, o valor literário das obras denunciadas e proibidas. $\mathrm{O}$ valor literário, sim. $\mathrm{O}$ argumento é bom, mas é insuficiente. Às vezes, esse argumento literário não passa mesmo de um pretexto para defender-se contra o terrorismo da polícia, da Justiça e da chamada opinião pública. A resposta mais certa deu o Supremo Tribunal da Noruega, em maio de 1958, julgando o processo contra o romance $A$ canção do rubi vermelho, de Agnar Mykle, denunciado por descrever "manipulações com os órgãos sexuais e cópulas em várias posições". Decidiram os juízes noruegueses que nem o valor literário de um livro nem a decência ou indecência de um escritor são argumentos no processo contra a liberdade de falar, garantida pela Constituição daquele país democrático. A liberdade, diziam os juízes de Oslo, é mais importante que a defesa da moralidade de solteironas e de hipócritas (CARPEAUX, 1975, p. 10-11).

Mais que a narrativa pornográfica reescrita por Henry Miller em $O$ mundo do sexo (1940), talvez o prefácio fosse o "responsável" pela censura do livro, pois o argumento de Carpeaux, acompanhando os juízes noruegueses, desautorizava a saída mais fácil para vetar qualquer romance pornográfico: a depreciação do valor literário. O argumento serve aqui tanto para os censores do DCDP quanto para os atuais críticos/censores literários que continuam a ignorar a importância da literatura de Cassandra e Adelaide para se compreender o problema da liberdade de expressão em regimes autoritários. Tomar o valor literário como ponto de partida parece por demais precipitado, para não dizer

\footnotetext{
${ }^{10}$ Segundo Reimão $(2011$, p. 48), três autores nacionais tão censurados quanto Cassandra e Adelaide se valeram de pseudônimos: Dr. G. Pop, Brigitte Bijou e Márcia Fagundes Varella. Isto certamente os poupou de prestar depoimentos à polícia, pagar multas, entre outras humilhações. No caso de Cassandra, além do nome artístico (Cassandra é, na verdade, Odete Rios), a autora utilizou dois pseudônimos para publicar romances de temática heterossexual: Clarence Rivier e Oliver Rivers. Entretanto, ao contrário do que afirmam Moraes e Lapeiz (1991, p. 163), provavelmente a intenção de Cassandra não era burlar a censura, pois ela adotou os pseudônimos ao final dos anos 1970, ou seja, quando a censura de diversões públicas começou a abrandar (o Decreto-lei n. 1.077 perdeu a eficácia em 26 de fevereiro de 1980). Provavelmente os motivos dos pseudônimos se deviam à temática heterossexual, visto que o nome "Cassandra Rios" se ligava quase exclusivamente aos seus romances homossexuais femininos. Em entrevista ao jornal Pasquim (20 a 26 de agosto de 1976), Cassandra disse o seguinte a respeito de adotar pseudônimo: "Isto seria burlar o governo. Eu jamais faria isso. (...) Sempre quis estar dentro da lei. E dou valor, amo o que faço" (RIOS, 1976, p. 8).
}

Revista Eletrônica Literatura e Autoritarismo, no 21- Janeiro-Junho de 2013 - ISSN 1679-849X |145 http://cascavel.ufsm.br/revistas/ojs-2.2.2/index.php/LA/about/index 
insensato, quando a liberdade de expressão se encontra ameaçada, pois sem liberdade de expressão, nenhuma manifestação artística é possível. Neste sentido, o problema da liberdade de expressão compete diretamente à crítica literária, pois considerar o contrário é enclausurar a literatura em uma concepção alheia da realidade.

Ainda que referente a um autor aclamado pela crítica literária, a posição incondicional de Carpeaux era rara entre os intelectuais, principalmente depois do Al-5, quando um quadro aparentemente difícil de compreender ganhava contornos sólidos: enquanto a censura, de algum modo, "reconhecia" a obra de autoras como Cassandra e Adelaide no momento da proibição, os intelectuais preferiam ignorá-las por completo. Dizer isto não implica em favorecer a censura do Estado perante a "censura" dos intelectuais (apesar de ignorá-las, eles não roubavam os meios de subsistência das autoras), mas simplesmente indicar a cumplicidade entre ambas: a suposta indiferença dos intelectuais correspondia ao gradual sumiço das obras das autoras promovido pelo Estado. De tanto ignorá-las, elas quase deixaram de existir.

A simbiose entre intelectuais e Estado mostra como este, através da censura, defendia os interesses da classe dominante, inclusive dos intelectuais: se os intelectuais faziam vista grossa quando o Estado proibia o erotismo dos pobres, então é porque o Estado realmente atendia as expectativas dos intelectuais, ou melhor, não as contrariava. É claro que uma vez ou outra os dois se encontravam em lados opostos, mas essas exceções apenas confirmavam a regra. Se muitas vezes carecia aos técnicos de censura formação artística suficiente para diferenciar Picasso e Cassandra, então a indignação dos intelectuais em relação à proibição das gravuras eróticas do primeiro e o absoluto silêncio em relação à proibição dos romances da segunda indicava aos técnicos quando eles "acertavam" ou "erravam". Segundo Silva,

ainda assim, a questão de separar o pornográfico do artístico continua complicada. (...) Continua-se, pois, insolitamente, a tolerar a censura quando a obra de ficção perseguida é caracterizada como pornográfica. Deslinda-se, assim, a mecânica de poder inerente à questão. As constantes alusões ao prestígio dos escritores censurados, o rastreamento de seu passado literário, suas práticas como cidadãos e diversos outros quesitos disfarçam a questão maior: não se busca defender a liberdade de expressão artística, a não ser na medida em que, à luz de critérios, extremamente polêmicos, busca-se separar o pornográfico do artístico (SILVA, 1989, p. 49-50; grifo do autor).

Revista Eletrônica Literatura e Autoritarismo, no 21- Janeiro-Junho de 2013 - ISSN 1679-849X 146 http://cascavel.ufsm.br/revistas/ojs-2.2.2/index.php/LA/about/index 
A indignação ou o silêncio dos intelectuais servia para esses propósitos, pois, ao invés de defender a liberdade de expressão artística, separava-se o pornográfico do artístico. Por meio desta separação, os censores orientavam seus trabalhos.

Não se quer aqui atribuir aos intelectuais uma força que eles jamais tiveram, pois mesmo que defendessem as obras de Cassandra e Adelaide, dificilmente conseguiriam algum resultado (não o conseguiram em relação aos livros de Rubem Fonseca e Ignácio de Loyola Brandão, Feliz ano novo e Zero). Tentou-se demonstrar, por meio deste artigo, a origem dessa indiferença e como ela persiste, negando hoje a contribuição dos romances populares pornográficos para se compreender o contexto histórico-literário do regime de 64 .

\section{Referências}

ALVES, Maria Helena Moreira. Estado e oposição no Brasil (1964-1984). Bauru: Edusc, 2005.

ARRIGUCCI JR., Davi. Achados e perdidos: ensaios de crítica. São Paulo: Polis, 1979.

BAHIANA, Ana Maria. Almanaque Anos 70. Rio de Janeiro: Ediouro, 2006.

BOSI, Ecléa. Cultura de massa e cultura popular: leituras de operárias. Petrópolis: Vozes, 2000.

CALDAS, Waldenyr. O sucesso dos esquecidos. In: FERREIRA, Jerusa Pires; MILANESI, Luís (Org.). O obsceno: jornadas impertinentes. São Paulo: Hucitec, s/d.

CANDIDO, Antonio. A literatura brasileira em 1972. Revista Ibero-americana, n. 98-99, p. 5-16, jun. 1977.

CARPEAUX, Otto Maria. Henry Miller: literatura ou pornografia? In: MILLER, Henry. 0 mundo do sexo. Tradução Carlos Lage. Rio de Janeiro: Americana, 1975.

DUCLÓS, Nei. Abre mais. Folha de S. Paulo, São Paulo, 18 fev., 1979. Folhetim, p. 13.

FRANCO, Renato. Itinerário político do romance pós-64: A festa. São Paulo: Ed. UNESP, 1998.

GONÇALO JUNIOR. Malditas escritoras. Jornal da ABI, Rio de Janeiro, n. 378, p. 30-32, mai. 2012. 
HOGGART, Richard. The uses of literacy: aspects of working-class life with special reference to publications and entertainments. Harmondsworth: Penguin, 1981.

HOLLANDA, Heloísa Buarque de; GONÇALVES, Marcos Augusto de. Política e literatura: a ficção da realidade brasileira. In: NOVAES, Adauto (Org.). Anos 70: literatura. Rio de Janeiro: Europa, 1980.

HORKHEIMER, Max; ADORNO, Theodor W. A indústria cultural: o lluminismo como mistificação de massa. Tradução Júlia Elisabeth Levy. In: LIMA, Luiz Costa (Org.). Teoria da cultura de massa. Rio de Janeiro: Saga, 1969.

LONDERO, Rodolfo Rorato. Base-superestrutura: modos de usar. In: PEREIRA, Ariane et al. (Org.). A trama das humanidades: olhares, discursos, intervenções. Guarapuava: Ed. Unicentro, 2010.

MARCELINO, Douglas Attila. Salvando a pátria da pornografia e da subversão: a censura de livros e diversões públicas nos anos 1970. Rio de Janeiro: UFRJ, 2006. 300 p. Dissertação (Mestrado) - Programa de Pós-Graduação em História Social, Universidade Federal do Rio de Janeiro, Rio de Janeiro, 2006.

MARTÍN-BARBERO, Jesús. Dos meios às mediações: comunicação, cultura e hegemonia. Tradução Ronald Polito; Sérgio Alcides. Rio de Janeiro: Ed. UFRJ, 2006.

MORAES, Eliane R.; LAPEIZ, Sandra M. O que é pornografia. São Paulo: Círculo do Livro, 1991.

NAPOLITANO, Marcos. "Vencer Satã só com orações": políticas culturais e cultura de oposição no Brasil dos anos 1970. In: ROLLEMBERG, Denise; QUADRAT, Samantha Viz (Org.). A construção social dos regimes autoritários: Brasil e América Latina. Rio de Janeiro: Civilização Brasileira, 2010.

PELLEGRINI, Tânia. Gavetas vazias: ficção e política nos anos 70 . São Carlos: EDUFSCar, 1996.

Despropósitos: estudos de ficção brasileira contemporânea. São Paulo: Annablume, 2008.

PIOVEZAN, Adriane. Amor romântico $\mathbf{x}$ deleite dos sentidos: Cassandra Rios e a identidade homoerótica feminina na literatura (1948-1972). Curitiba: UFPR, 2005. 105 p. Dissertação (Mestrado) - Programa de Pós-Graduação em Estudos Literários, Universidade Federal do Paraná, Curitiba, 2005.

REIMÃO, Sandra. Repressão e resistência: censura a livros na ditadura militar. São Paulo: Edusp, 2011.

RIOS, Cassandra. Cassandra Rios. Pasquim, Rio de Janeiro, n. 373, p. 6-9, ago. 1976. Entrevista concedida a Ione Cirilo.

Fernando Luna.

A perseguida. TPM, São Paulo, n. 3, p. 4-13, jul. 2001. Entrevista concedida a

Revista Eletrônica Literatura e Autoritarismo, no 21- Janeiro-Junho de 2013 - ISSN 1679-849X $\mid 148$ http://cascavel.ufsm.br/revistas/ojs-2.2.2/index.php/LA/about/index 
ROLLEMBERG, Denise; QUADRAT, Samantha Viz. Apresentação. In: ROLLEMBERG, Denise; QUADRAT, Samantha Viz (Org.). A construção social dos regimes autoritários: Brasil e América Latina. Rio de Janeiro: Civilização Brasileira, 2010.

SANTOS, Rick J. Apresentação crítica e atualizada desta edição. In: RIOS, Cassandra. Uma mulher diferente. São Paulo: Brasiliense, 2005.

SILVA, Deonísio da. Nos bastidores da censura: sexualidade, literatura e repressão pós-64. São Paulo: Estação Liberdade, 1989.

SÜSSEKIND, Flora. Literatura e vida literária: polêmicas, diários \& retratos. Belo Horizonte: Ed. UFMG, 2004.

VENTURA, Zuenir. O vazio cultural. In: GASPARI, Elio; HOLLANDA, Heloísa Buarque de; VENTURA, Zuenir. Cultura em trânsito: da repressão à abertura. Rio de Janeiro: Aeroplano, 2000.

1968: o ano que não terminou. São Paulo: Planeta, 2008.

VIEIRA, Pedro de Castro Amaral. Meninas más, mulheres nuas: Adelaide Carraro e Cassandra Rios no panorama literário brasileiro. Rio de Janeiro: PUC-Rio, 2010. 159 p. Tese (Doutorado) - Programa de Pós-Graduação em Letras, Pontifícia Universidade Católica do Rio de Janeiro, Rio de Janeiro, 2010.

WATT, Ian. A ascensão do romance: estudos sobre Defoe, Richardson e Fielding. Tradução Hildegard Feist. São Paulo: Companhia das Letras, 2007. 